\title{
Effect of Hot Charge Rolling Condition on Mechanical Properties of Nb Bearing Steel Plate
}

\section{Yoshihiko KAMADA, Tamotsu HASHIMOTO and Seiichi WATANABE'1)}

Iron \& Steel Research Laboratories, Sumitomo Metal Industries, Ltd., Nishinagasu-hondori, Amagasaki, Hyogo-ken, 660 Japan. 1) Advanced Technology Research Laboratory, Sumitomo Metal Industries, Ltd., Nishinagasu-hondori, Amagasaki, Hyogo-ken, 660 Japan.

(Received on July 10, 1989; accepted in the final form on September 8,1989)

\begin{abstract}
A large number of steel plates is currently produced by HCR(Hot Charge Rolling) process. In this study, the effect of $\mathrm{HCR}$ condition on the mechanical properties of $\mathrm{Nb}$ bearing steel is investigated.

If the charging temperature is above $A r_{1}$, the toughness of $\mathrm{Nb}$ bearing steel through HCR process is inferior to conventionally rolled one. This phenomenon comes from the larger amount of $\mathrm{Nb}$ in solid solution in the HCR process than in the CCR(Cold Charged Rolling) process. This Nb in solid solution markedly retards the recrystallization of austenite and then it precipitates finely as $\mathrm{Nb}(\mathrm{CN})$ after rolling in the HCR process. To improve the balance between the tensile strength and ductile-brittle transition temperature in $\mathrm{Nb}$ bearing steel at a charging temperature above $A r_{1}, 1100^{\circ} \mathrm{C}$ is the most favorable for the rolling start temperature, because the finest austenite grain is obtained at this temperature range due to the homogeneous recrystallization.
\end{abstract}

KEY WORDS: high strength low alloy steel; plate; phase transformation; precipitation; recrystallization; strength; toughness.

\section{Introduction}

The manufacturing process of steel products has undergone profound changes from the standpoint of saving energy, and recently Hot Charge Rolling process (HCR) has been introduced. ${ }^{1)}$ HCR process is a new rolling process, connecting the rolling process with the continuous casting process. In this process, continuous cast slabs are directly charged to furnace to roll without cooling until ambient temperature. ${ }^{2)}$

In order to attain an optimum balance between strength and toughness, High Strength Low Alloy (HSLA) steels have been produced by controlling the microalloying and the thermomechanical treatment. If HSLA steels are made through HCR process, then it is reasonable to think that the mechanical properties of these steels may be different from that of cold charged rolling (GCR) processed materials which is conventional process. Because the austenite before rolling shows a larger grain size and contains a larger amount of microalloy in solid solution compared with that of CCR processed materials. ${ }^{3-5)}$

There are hitherto many papers on hot cracking of continuously cast HSLA steels, but few papers on mechanical properties of hot charge rolled HSLA steels. $^{6-8)}$

In this paper, the effect of hot charge rolling condition on mechanical properties of $\mathrm{Nb}$ bearing steel was examined, comparing their recrystallization during rolling. ${ }^{9)}$ Then the optimum rolling condition for $\mathrm{Nb}$ bearing steel through $\mathrm{HCR}$ process are discussed.

\section{Experimental Procedure}

\subsection{Hot Rolling Experiment}

Two kinds of steels are used in this experiment whose chemical composition is listed in Table 1 , consisting of $0.03 \% \mathrm{Nb}$ bearing steel ( $\mathrm{Nb}$ steel) and plain carbon steel (10C steel). These steels were melt in argon atmosphere and in a vacuum by using 200 and $50 \mathrm{~kg}$ induction heating furnaces, and cast into eleven and three metal molds, respectively, whose ingot shape is $100 \mathrm{~mm}$ square and $200 \mathrm{~mm}$ high. In order to measure the cooling speed and $A r_{3}, A r_{1}$ transformation temperature of these steels after solidification, the thermocouple- $\mathrm{R}(0.5 \mathrm{~mm}$ in diameter) within alumina crucible was set in the center of one of those mold. After solidification, they were immediately removed from the mold, and charge to electric furnace at a various charging temperature which was surface temperature of them. Slabs were heated up to $T_{h}{ }^{\circ} \mathrm{G}$ and kept for $1 \mathrm{~h}$. Then they were rolled to $15 \mathrm{~mm}$ thick plates through 14 passes. In the rolling process, two stage of control rolling were adopted. On the first stage, they were rolled to 45 $\mathrm{mm}$ thick plates through 6 passes above $850^{\circ} \mathrm{C}$, then

Table 1. Chemical composition. (wt\%)

\begin{tabular}{lcccccccc}
\hline Steel & $\mathrm{C}$ & $\mathrm{Si}$ & $\mathrm{Mn}$ & $\mathrm{P}$ & $\mathrm{S}$ & $\mathrm{Nb}$ & Sol. Al & $\mathrm{N}$ \\
\hline 10C1 & 0.09 & 0.27 & 1.32 & 0.008 & 0.007 & - & 0.021 & 0.007 \\
Nb1 & 0.09 & 0.21 & 1.34 & 0.003 & 0.005 & 0.034 & 0.025 & 0.005 \\
10C2 & 0.10 & 0.31 & 1.44 & 0.003 & 0.006 & - & 0.028 & 0.007 \\
Nb2 & 0.09 & 0.29 & 1.43 & 0.004 & 0.003 & 0.036 & 0.023 & 0.007 \\
Nb3 & 0.11 & 0.25 & 1.35 & 0.002 & 0.003 & 0.029 & 0.020 & 0.002 \\
\hline
\end{tabular}




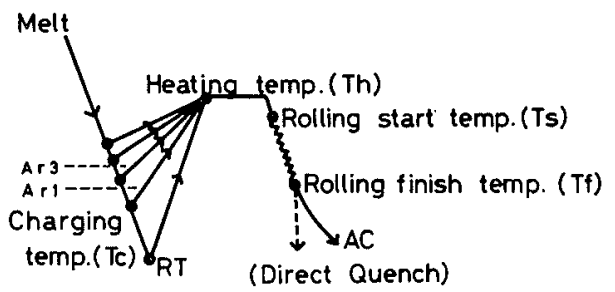

Fig. 1. Laboratory simulation method for hot charge rolling and conventional rolling processes.

rolled to $15 \mathrm{~mm}$ thick plates through the next 8 passes from 850 to $750^{\circ} \mathrm{C}$ (or $780^{\circ} \mathrm{C}$ ) on the second stage. The heat cycle of hot rolled steel plates in this experiment is shown in Fig. 1.

Mechanical properties were determined from transverce tensile specimen $(8.5 \mathrm{~mm}$ in diameter) and longitudinal Charpy specimen (2 $\mathrm{mm} \mathrm{V}$ notch) machined from the center of plates. The microstructures were characterized by optical metallography of longitudinal section, and ferrite grain size was measured by means of linear analysis method. The distribution of precipitates was examined by transmission electron microscopy (TEM).

$\mathrm{Nb}$ compound was analyzed by using electrolysis method employing $10 \%$ acetyle aceton-1 \% tetramethyle ammonium chloride-methanol solution. Soluble $\mathrm{Nb}$ was analyzed by measuring $\mathrm{Nb}$ content in the solution filtered through $0.2 \mu \mathrm{m}$ meshed filter. ${ }^{10)}$

And further, in order to study a change in recrystallization process with hot rolling in HCR process, Nb6 and 10C4 steels were directly quenched after rolling with the rolling finish temperature of $800^{\circ} \mathrm{C}$, and the cross section of them was cut, polished, and etched by $20 \%$ nitric acid solution for $2 \mathrm{~min}$, then the ratio of recrystallized region was measured.

\subsection{Interrupted Compression Test}

The chemical composition of steels used is listed in Table 2. Though carbon and nitrogen contents of $\mathrm{Nb5}$ are extremely lower than that of $\mathrm{Nb} 4$, it was prepared to study the effect of $\mathrm{Nb}$ in solid solution on the recrystallization process. As the solution temperature of $\mathrm{Nb}(\mathrm{CN})$ for $\mathrm{Nb} 5$ is calculated to be $744^{\circ} \mathrm{C}$ from the solubility product, ${ }^{11}$ ) the precipitation of $\mathrm{Nb}$ $(\mathrm{CN})$ cannot occur at the temperature range above $750^{\circ} \mathrm{C}$.

The interrupted compression test which is illustrated in Fig. 2 was carried out by using a hot deformation simulator (THERMEGMASTER-Z: Fuji Electric Ind. Co., Ltd.) to compare the recrystallization process of these steels by measuring the softening ratio which is represented by $\mathrm{Eq} .(1) \cdot{ }^{12,13)}$

$$
X s=\left(\sigma_{m}-\sigma_{2}\right) /\left(\sigma_{m}-\sigma_{1}\right)
$$

where, $\sigma_{m}$ : the maximum stress before unloading $\sigma_{1}, \sigma_{2}:$ the initial yield stresses during prestraining and reloading, respectively.

In this testing, the cylindrical specimens, $8 \mathrm{~mm}$ in diameter and $12 \mathrm{~mm}$ high, were used, and the loading were carried out with strain rate of $1 / \mathrm{s}$.
Table 2. Chemical composition. (wt\%)

\begin{tabular}{llccccccc}
\hline Steel & \multicolumn{1}{c}{$\mathrm{C}$} & $\mathrm{Si}$ & $\mathrm{Mn}$ & $\mathrm{P}$ & $\mathrm{S}$ & $\mathrm{Nb}$ & $\mathrm{Sol} . \mathrm{Al}$ & $\mathrm{N}$ \\
\hline 10C3 & 0.10 & 0.29 & 1.35 & 0.003 & 0.003 & - & 0.028 & 0.002 \\
Nb4 & 0.10 & 0.23 & 1.34 & 0.002 & 0.003 & 0.030 & 0.015 & 0.005 \\
Nb5 & 0.0006 & 0.22 & 1.33 & 0.001 & 0.003 & 0.026 & 0.016 & 0.001 \\
\hline
\end{tabular}
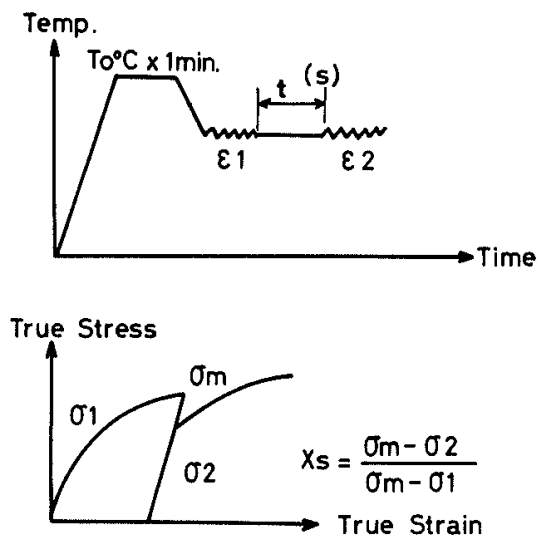

Fig. 2. Schematic representation of interrupted compression testing method.

\section{Experimental Results}

\subsection{Effect of Charging Temperature $\left(T_{c}\right)$ on Strength and Toughness}

The effect of charging temperature $\left(T_{c}\right)$ on tensile strength $(T S)$ and brittle-ductile transition temperature ( $\mathrm{v} T \mathrm{~s}$ ) of Nb1 steel is shown in Fig. 3, comparing with that of $10 \mathrm{Cl}$ steel. The $v T_{\mathrm{s}}$ for $\mathrm{Nbl}$ and $10 \mathrm{Cl}$ steels increases when the charging temperature is raised from 600 to $650^{\circ} \mathrm{G}$. In the case of $T_{c}=600^{\circ} \mathrm{C}$, the $\gamma-\alpha$ transformation has been finished since the $A r_{1}$ temperature of $\mathrm{Nb}$ and $10 \mathrm{Cl}$ steels were measured to be 609 and $601^{\circ} \mathrm{C}$, respectively.

Meanwhile, when the charging temperature is raised from below $600^{\circ} \mathrm{C}$ to above $650^{\circ} \mathrm{C}$, the $T S$ of $\mathrm{Nbl}$ steel increases by $3-4 \mathrm{kgf} / \mathrm{mm}^{2}$ than that in case of $T_{c}$ below $600^{\circ} \mathrm{C}$. In case of $T_{c}$ above $650^{\circ} \mathrm{G}$, the $\gamma-\alpha$ transformation of $\mathrm{Nbl}$ steel has not occurred or completed since the $A r_{3}$ temperature was measured to be $671^{\circ} \mathrm{C}$. But $T S$ of $10 \mathrm{Cl}$ steel shows constant with no dependency of $T_{c}$ temperature. Fig. 4 shows the change in microstructure for $\mathrm{Nbl}$ and $10 \mathrm{Cl}$ steels with $T_{c}$ temperature. Ferrite grain size of both steels in case of $T_{c}=1000^{\circ} \mathrm{C}$ is larger than that in case of ambient $T_{c}$ temperature. And further $\mathrm{Nb1}$ steel shows inhomogeneous microstructure but $10 \mathrm{Cl}$ steel shows homogeneous one.

In this way, the change in mechanical property and microstructure of HCR processed steels is greatly depended upon the charging temperature $\mathcal{T}_{c}$, and the dependency is most steep with $\mathcal{T}_{c}$ around $A r_{1}$.

\subsection{Effect of Heating Temperature $\left(\mathcal{T}_{h}\right)$ on Strength and Toughness}

It is observed that the mechanical properties and microstructure of $\mathrm{HCR}$ processed $\mathrm{Nb}$ steel change steeply with $T_{c}$. It is reasonable to think that this change is due to the precipitation as well as the solu- 
tion of $\mathrm{Nb}$ during the cooling process after solidification and the heating process before rolling. Therefore, the effect of heating temperature $\left(T_{h}\right)$ on the relation between $T S$ and $\mathrm{v} T \mathrm{~s}$ of $\mathrm{Nb}$ steel was examined. The result is shown in Fig. 5 with the reference of carbon steel 10G. 10G steel does not show much change in the relation between $T S$ and $\mathrm{v} \mathcal{T}_{\mathrm{s}}$ with heating temperature $\left(T_{h}\right)$, but $\mathrm{Nb}$ steel shows a change in the relation with the change of $\tau_{c}$. As a result, the following description focuses on $\mathrm{Nb}$ steel. In case of $\tau_{c}$, ambient temperature, TS of $\mathrm{Nb}$ steel increases and the $\mathrm{v} T \mathrm{~s}$ shifts to higher temperature with a rise in $T_{l}$. In case of $T_{c}, 900^{\circ} \mathrm{C}$, the $T S$ increases but the $v \mathcal{T}_{\mathrm{s}}$ does not show much change with a rise in $T_{h}$. And in case of $T_{c}, 1000^{\circ} \mathrm{C}$, the

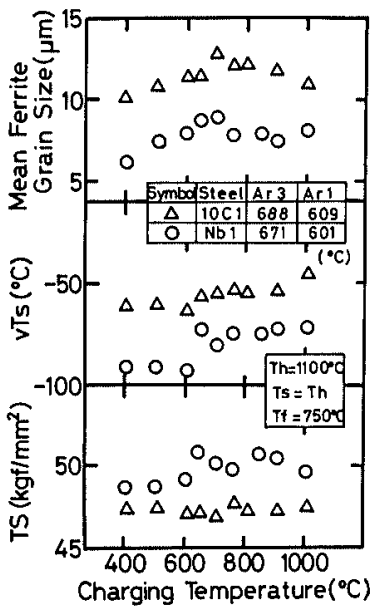

Fig. 3. Effect of charging temperature $\left(T_{c}\right)$ on mechanical properties of $10 \mathrm{Cl}$ and $\mathrm{Nb} 1$ steel.
$T S$ shows high independently of $T_{h}$ but the $\mathrm{v} T_{\mathrm{s}}$ shifts to lower temperature with a rise in $T_{h}$. Moreover, even when $T_{h}$ is $1200^{\circ} \mathrm{C}$ where $\mathrm{Nb}$ precipitates are considered to dissolve completely in austenite according to the calculation of solubility products, ${ }^{11)}$ TS of HCR processed material with the charging temperature above $A r_{1}$ keeps still higher by about $2 \mathrm{kgf} / \mathrm{mm}^{2}$ than that of conventional one.

Fig. 6 shows the change in microstructure with $T_{h}$, where $T_{c}$ is $1000^{\circ} \mathrm{C}$. These microstructures consist of mix-sized grains of ferrite and pearlite, but the microstructures change more homogeneous and finer with a rise in $T_{h}$. This change well explains the improvement in $\mathrm{v} T \mathrm{~s}$.

\subsection{Effect of Rolling Start Temperature $\left(\mathcal{T}_{s}\right)$ on Strength and Toughness}

In case of $T_{c}$ above $A r_{3}$, the relation between $T S$

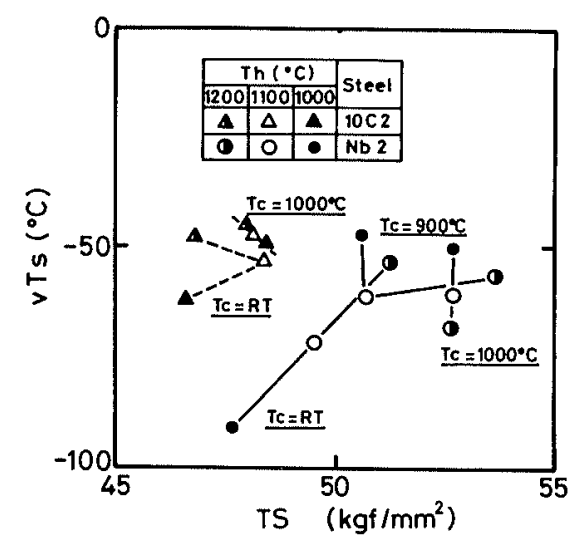

Fig. 5. Effect of heating temperature $\left(T_{h}\right)$ on $T S-v T_{s}$ balance of $10 \mathrm{C} 2$ and $\mathrm{Nb} 2$ steels.

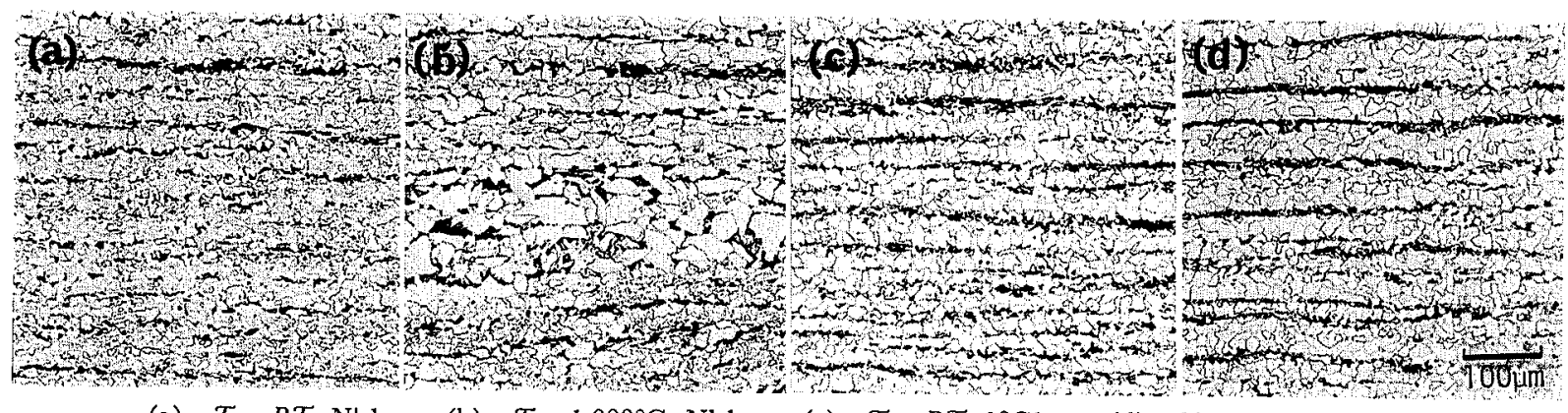
(a) $T_{c}=R T: \mathrm{Nb} 1$,
(b) $T_{\mathrm{e}}=1000^{\circ} \mathrm{C}: \mathrm{Nbl}$,
(c) $T_{c}=R T: 10 \mathrm{Cl}$,
(d) $T_{c}=1000^{\circ} \mathrm{C}: 10 \mathrm{Cl}$

$$
T_{h}=1100^{\circ} \mathrm{C}, \quad T_{s}=T_{h}, \quad T_{f}=750^{\circ} \mathrm{C}
$$

Fig. 4. Change of optical microstructures of $10 \mathrm{Cl}$ and $\mathrm{NbI}$ steels with $T_{c}$.

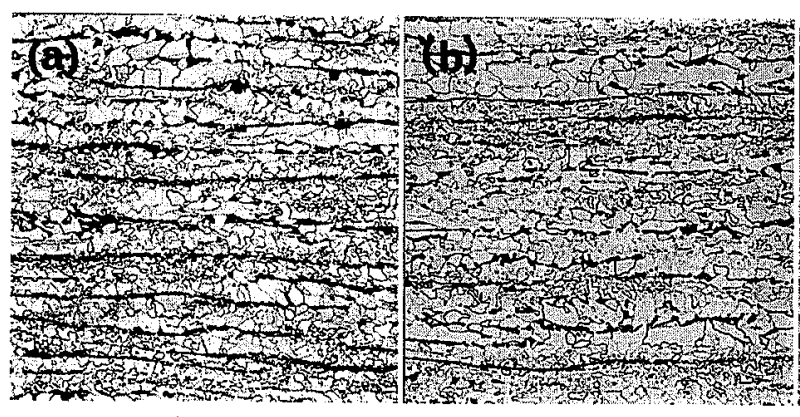

(a) $T_{h}=1200^{\circ} \mathrm{C}: \mathrm{Nb} 2$, (b) $T_{h}=1000^{\circ} \mathrm{C}: \mathrm{Nb} 2$,

$T_{c}=1000^{\circ} \mathrm{C}, \quad T_{s}=T_{n}$

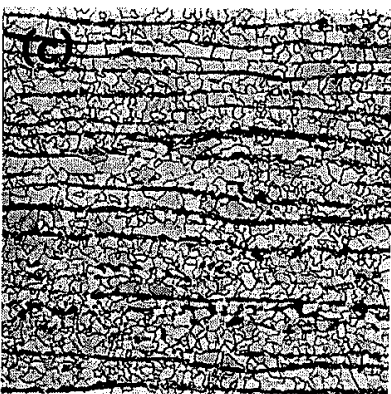

(c) $T_{h}=1200^{\circ} \mathrm{C}: 10 \mathrm{C} 2$,

$T_{f}=750^{\circ} \mathrm{G}$

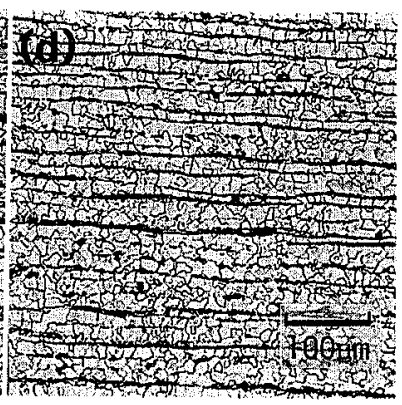

(d) $T_{h}=1000^{\circ} \mathrm{C}: 10 \mathrm{C} 2$

Fig. 6. Change of optical microstructures of $10 \mathrm{C} 2$ and $\mathrm{Nb} 2$ steels with $T_{h}$. 
and $\mathrm{v} T_{\mathrm{s}}$ of HCR processed $\mathrm{Nb}$ steel is improved with a rise in $T_{h}$. This suggests that hot working at higher temperature region has good influence on the microstructure. Fig. 7 shows the effect of rolling start temperature $\left(T_{s}\right)$ on $T S$ and $\mathrm{v} T \mathrm{~s}$ for $\mathrm{Nb}$ steel. In this experiment, the rolling finish temperature is raised to $780^{\circ} \mathrm{C}$ to deform only austenite phase, the meaning of which is mentioned later.

In GGR process, $T S$ increases and $v T_{s}$ shifts to higher temperature with a rise in $T_{h}$ due to the increase in the amount of $\mathrm{Nb}$ in solid solution, $\mathrm{v} \mathcal{T}_{\mathrm{S}}$ is improved with a decrease in $T_{s}$.

On the other hand, in HCR process, there is no change in $T S$ with $T_{h}$, but $\mathrm{v} T_{\mathrm{s}}$ is improved with a rise in $T_{s}$ until $1100^{\circ} \mathrm{C}$.

Fig. 8 shows the change in microstructure for HCR processed $\mathrm{Nb}$ steel with various rolling start temperature, where $T_{c}$ is $1000^{\circ} \mathrm{C}$. They show mixed size of ferrite and pearlite grains, and the area of mix-sized grains is increased with a decrease in $T_{s}$. Especially in case of rolling start temperature below $1000^{\circ} \mathrm{C}$, the microstructure shows mixed size of ferrite and pearlite grains and it seems that the inhomogeneous structure has been transformed from a large austenite grain. ${ }^{14,15}$ )

As mentioned above, TS and $v T$ s changes depending upon the rolling start temperature in spite of the same austenite grain size before rolling. So, it is suggested that the inhomogeneity in microstructure and the deterioration of $\mathrm{v} T_{\mathrm{S}}$ might be originated from not only $\gamma-\alpha$ transformation process but also recrystallization process due to hot rolling condition.

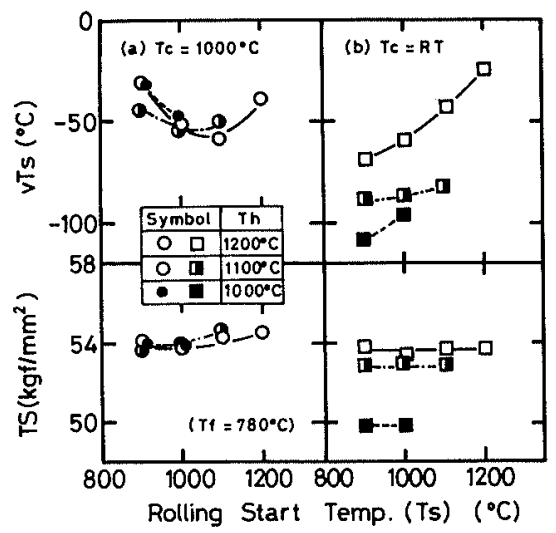

Fig. 7. Effect of rolling start temperature $\left(T_{s}\right)$ on mechanical properties of $\mathrm{Nb} 3$ steel.

\subsection{Difference in Recrystallization Process between HCR and $C C R$}

Fig. 9 shows the effect of rolling start temperature and rolling reduction on the ratio of recrystallized region for HCR processed $\mathrm{Nb} 6$ and $10 \mathrm{C} 4$ steels, where $T_{c} 1000^{\circ} \mathrm{C}, T_{h} 1100^{\circ} \mathrm{G}$, and $T_{f} 800^{\circ} \mathrm{C}$.

The ratio of recrystallized region for $10 \mathrm{C} 4$ steel increases with a rise in rolling start temperature and with increase in rolling reduction. On the other hand, the recrystallization in $\mathrm{Nb} 6$ steel scarcely occurs in case of the rolling start temperature below $1000^{\circ} \mathrm{C}$, but it occurs in the rolling start temperature of $1100^{\circ} \mathrm{C}$. It is shown that the increase in rolling reduction promotes the recrystallization. Fig. 10 shows some example of the etched cross section for Nb6 steel. The initiation site of recrystallization greatly depends upon the solidification structure. The initiation has turned out to be at the region of equiaxial structure in the center of ingot, and then it propagates outwards to the region of columnar structure as the rolling temperature is raised, or the rolling reduction is increased. In the outer columnar structure, the recrystallization initiates at the grain boundary of columnar structure. This indicates that the strain is concentrated in the vicinity of grain boundary when large austenite grain is hot worked.

In order to compare the recrystallization process in HCR process with that in GCR process, the interrupted compression testing is carried out by using a hot deformation simulator. As shown in Fig. 2, the specimen heated up to $1350^{\circ} \mathrm{C}$ for $1 \mathrm{~min}$ and $1100^{\circ} \mathrm{C}$

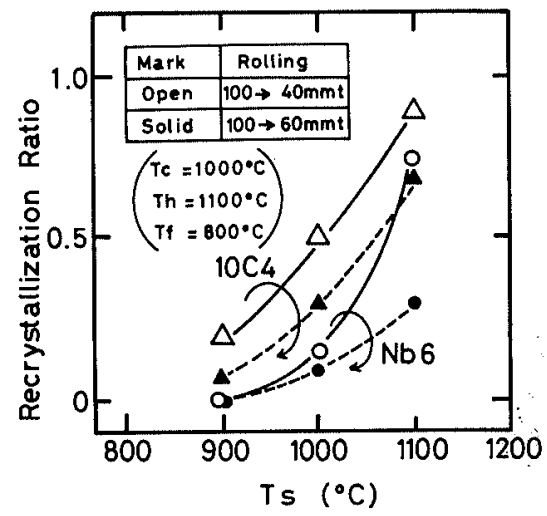

Fig. 9. Effect of rolling start temperature and rolling reduction on recrystallization ratio of $10 \mathrm{C} 4$ and $\mathrm{Nb} 6$ steels in hot charge rolling.

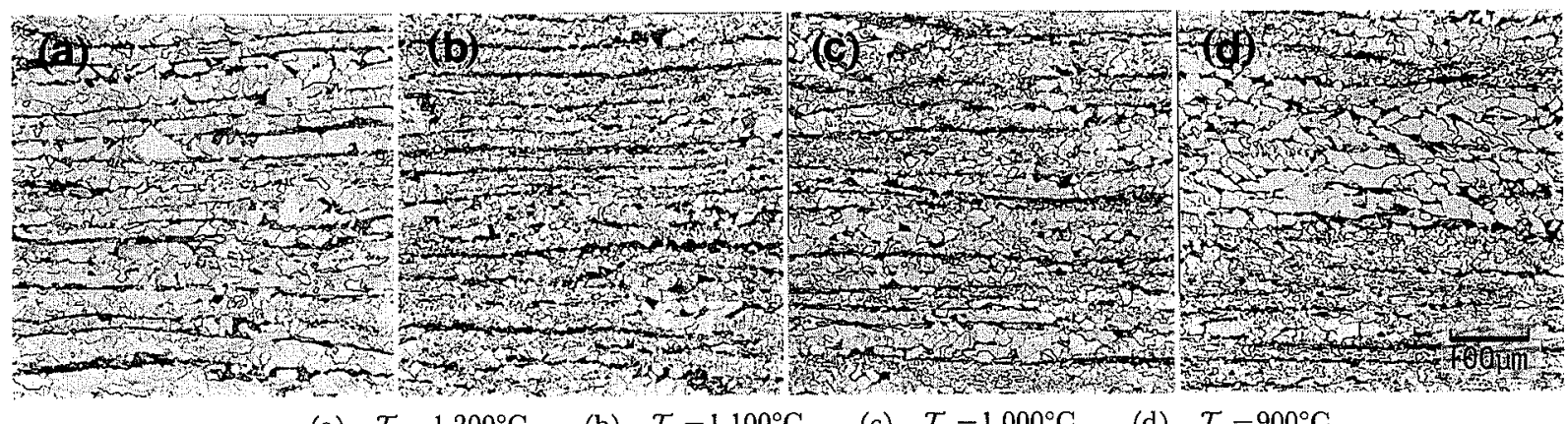
(a) $T_{s}=1200^{\circ} \mathrm{C}$
(b) $T_{s}=1100^{\circ} \mathrm{C}$
(c) $T_{s}=1000^{\circ} \mathrm{C}$
(d) $T_{s}=900^{\circ} \mathrm{C}$
$T_{c}=1000^{\circ} \mathrm{C}, \quad T_{h}=1200^{\circ} \mathrm{C}_{;}, \quad T_{f}=780^{\circ} \mathrm{C}$

Fig. 8. Change of optical microstructures of hot charge rolling processed Nb3 stectowith $T_{s}$. 

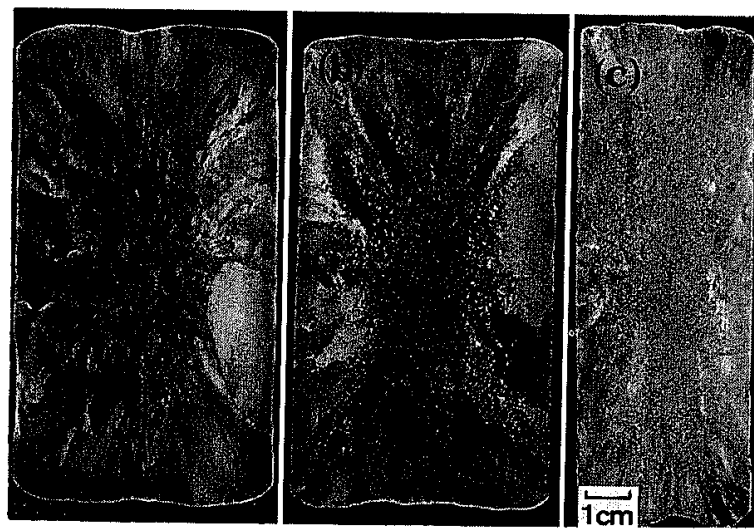

(a) $T_{s}=900^{\circ} \mathrm{G}$

(b) $T_{s}=1100^{\circ} \mathrm{C}: 100 \rightarrow 60 \mathrm{mmt}$

(c) $T_{s}=1100^{\circ} \mathrm{G}: 100 \rightarrow 40 \mathrm{mmt}$

$T_{c}=1000^{\circ} \mathrm{C}, \quad T_{h}=1100^{\circ} \mathrm{C}, \quad T_{f}=800^{\circ} \mathrm{C}$

Fig. 10. Change in recrystallization ratio of $\mathrm{Nb} 6$ steel with rolling start temperature and rolling reduction.

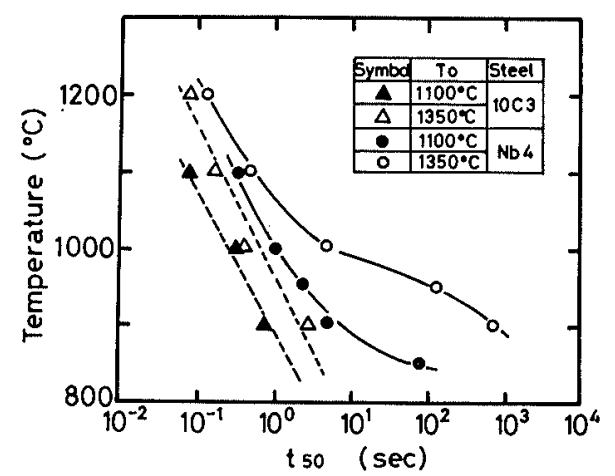

Fig. 11. Relation of half softening time, $t_{50}$, vs. deformation temperature for $10 \mathrm{C} 3$ and $\mathrm{Nb} 4$ steels.

for 1 min to simulate HCR process and CGR process, respectively. Then the austenite grain shows about $900 \mu \mathrm{m}$ in diameter for $1350^{\circ} \mathrm{C}$ heating and about $100 \mu \mathrm{m}$ in diameter for $1100^{\circ} \mathrm{C}$ heating. In $\mathrm{Nb} 4$ steel, it is calculated from solubility products ${ }^{11)}$ that $\mathrm{Nb}(\mathrm{CN})$ precipitates dissolves completely in austenite at $1350^{\circ} \mathrm{C}$ and the $70 \%$ of them dissolves at $1100^{\circ} \mathrm{C}$. The deformation is carried out at the temperature from 850 to $1200^{\circ} \mathrm{C}$. Fig. 11 shows the relation between $t_{50}$ and deformation temperature for these steels in the case of the prestrain 0.69. Here, $t_{50}$ is the interrupted time when the softening ratio reaches 0.5 .

The $t_{50}$ curves against deformation temperature for both steels are retarded with a rise in heating temperature. Especially in the case of Nb4 steel, the softening is retarded remarkably at the temperature range below $1000^{\circ} \mathrm{C}$. This method is an indirect method to estimate the recrystallization process. But the result well corresponds with the result in Fig. 6.

\section{Discussion}

\subsection{Strength of HCR Processed $\mathrm{Nb}$ Steel}

Solution temperature of $\mathrm{Nb}(\mathrm{CN})$ in $\mathrm{Nb} 2$ steel is calculated to be $1160^{\circ} \mathrm{G}$ according to Irvine's solubility products, ${ }^{11)}$ but $T S$ of HCR processed $\mathrm{Nb}$ steel

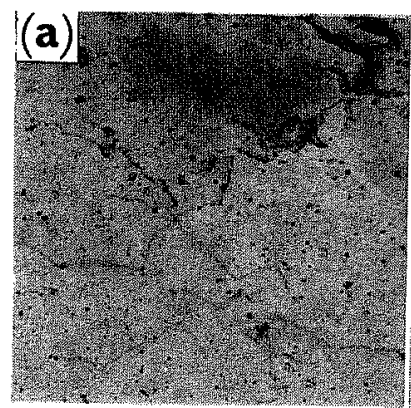

(a) $T_{c}=1000^{\circ} \mathrm{C}$

$T_{h}=1200^{\circ} \mathrm{C}, \quad T_{f}=750^{\circ} \mathrm{C}$

Fig. 12. Comparison of $\mathrm{Nb}(\mathrm{CN})$ particles in hot charge rolling processed and conventional rolling processed Nb2 steel.

keeps higher by $2 \mathrm{kgf} / \mathrm{mm}^{2}$ than GCR processed one even in case of $T_{h}$ is $1200^{\circ} \mathrm{C}$. Fig. 12 is TEM micrographs showing precipitates in HCR processed steel compared with GCR processed one. It is observed that row precipitation together with homogeneous precipitation occurred in HCR process, and the mean diameter of them is measured to be $27 \AA$. The diffraction pattern from these precipitates is shown in Fig. 13. The pattern is only one pair of spots, but correspond to interplaner spacing of $\mathrm{Nb}(\mathrm{CN})$.

In CCR process, fine particles precipitate in addition to coarse rounded particles whose diameter is about $100 \AA$. The total number of them are less than that in HCR process. The mean diameter of the precipitates in GGR processed steel is $40 \AA$. According to Kelly and Nicholson, ${ }^{16}$ ) it is calculated that the internal stress due to a misfit in $\alpha$-Fe matrix reaches maximum with the size ranging from 20 to $30 \AA .{ }^{17}$ ) This calculation suggests that increase in finely precipitated particles results in the rise in TS of HCR processed $\mathrm{Nb}$ steel in such a manner as HCR processed Ti bearing steel. ${ }^{5}$ Fig. 14 shows the relation between $T S$ and Sol.Nb/Total Nb for Nb3 steel shown in Fig. 9, but the data points are shown only in case of $T_{s}=T_{h}$ in order to eliminate the effect of rolling condition on $T S$.

It is required that the precipitation hardening caused from $\mathrm{Nb}(\mathrm{CN})$ precipitation after rolling is taken into consideration since these steels were air cooled after rolling. But in HCR process $T S$ and Sol. $\mathrm{Nb}$ do not change so much even when the heating temperature was raised from 1000 to $1200^{\circ} \mathrm{C}$, nevertheless, in GGR process they increase with a rise in heating temperature. And when the heating temperature is raised up to $1200^{\circ} \mathrm{G}$, the difference in TS between HCR and CGR becomes to be negligible. On the contrary, it is illustrated in Fig. 5 that there is still a difference in $T S$ between HCR and GGR even when the heating temperature was raised up to 1200 ${ }^{\circ} \mathrm{C}$. It is reasonable to think that this difference may originate from the shortage of heating time for the precipitates to dissolve, because the heating time is only $1 \mathrm{~h}$, and the $\mathrm{Nb}$ content of Nb2 steel shown in Fig. 5 was higher than that of Nb3 steel in Fig. 7. The difference in $T S$ will be negligitole if it is heated 

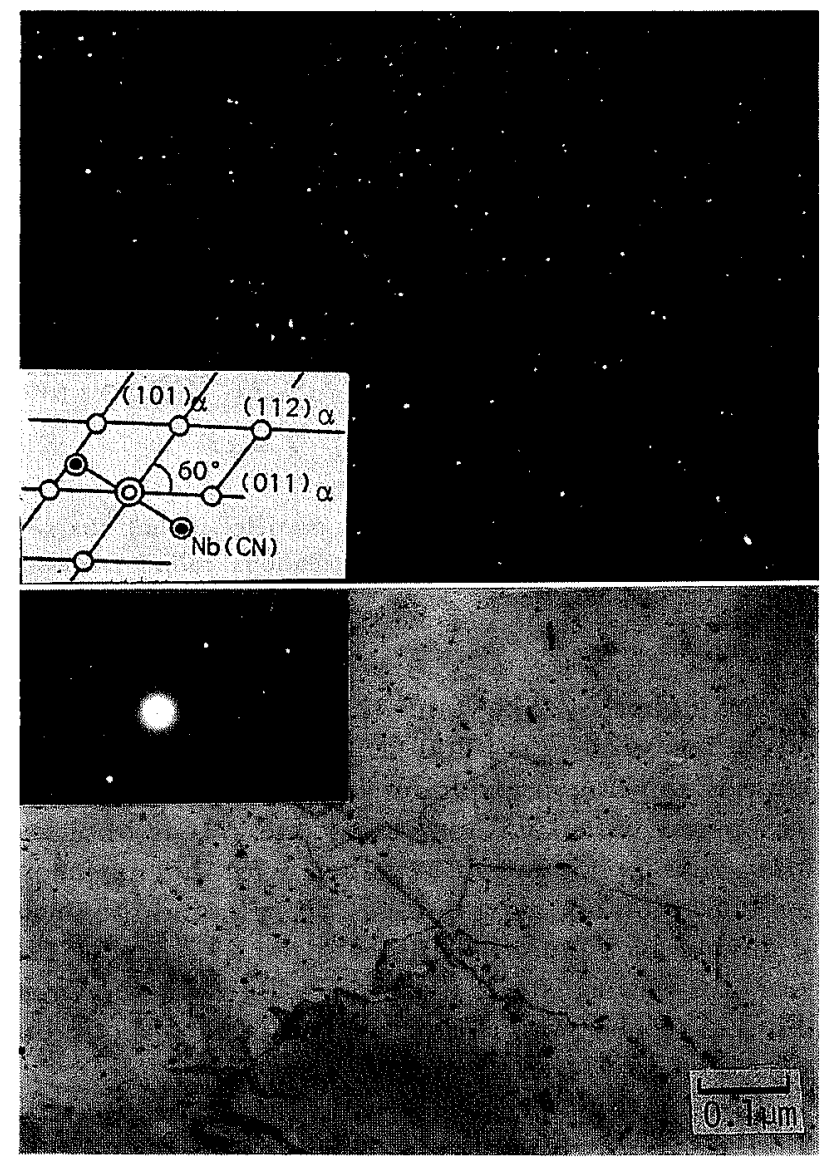

Fig. 13. $\mathrm{Nb}(\mathrm{CN})$ particles in hot charge rolling processed Nb3 steel

for enough long time and at enough high temperature for $\mathrm{Nb}(\mathrm{CN})$ precipitates to dissolve. Fig. 14 suggests that even when $\mathrm{Nb}$ steel is rolled in GCR process, the similar precipitation to that in HCR must be attained. The increase in TS of HCR processed $\mathrm{Nb}$ steel with $T_{c}$ above $A r_{1}$ appears to come from the precipitation hardening in ferrite matrix after $\gamma-\alpha$ transformation due to the excess amount of $\mathrm{Nb}$ in solid solution than that with $T_{c}$ below $A r_{1}$. On the contrary, it was reported that $T S$ of $\mathrm{HCR}$ processed $\mathrm{Nb}$ steel with $T_{c}$ above $A r_{1}$ decreased with increase in heating time, but this phenomenon is consistent with the result shown above. Because the decrease in $\mathcal{T S}$ with increase in heating time came from the precipitation of $\mathrm{Nb}(\mathrm{CN})$ in austenite which have a dull effect on the hardening. So, in order to utilize the increase in $T S$ of $\mathrm{Nb}$ steel through HCR process, it is required that the cast slabs must be charged to furnace with the charging temperature above $A r_{1}$. If the heating before rolling is carried out for so long time like plate rolling, then it is required that they must be charged to a furnace with the charging temperature above $900^{\circ} \mathrm{C}$ and heated at quite high temperature even in HGR process in order to keep the amount of $\mathrm{Nb}$ in solid solution.

\subsection{Toughness of HCR Processed Nb Steel}

Fig. 15 shows the Arrhenius plot of the reciprocal of half softening time, $1 / t_{50}$, vs. deformation temperature in Kelvin, $\mathrm{K}$, assuming that the recrystallization

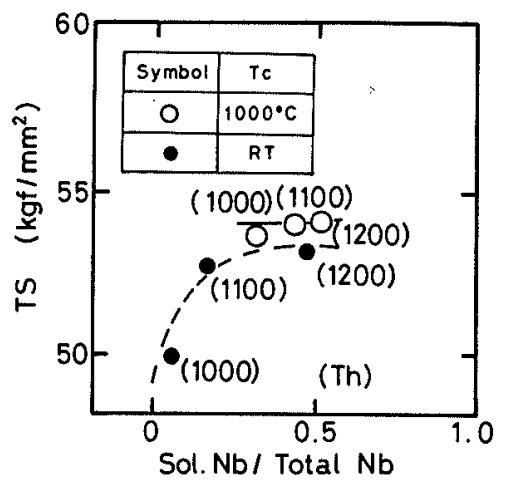

Fig. 14. Relation between TS and Sol. Nb/Total $\mathrm{Nb}$ of $\mathrm{Nb} 3$ steel in hot charge rolling and conventional rolling processes.

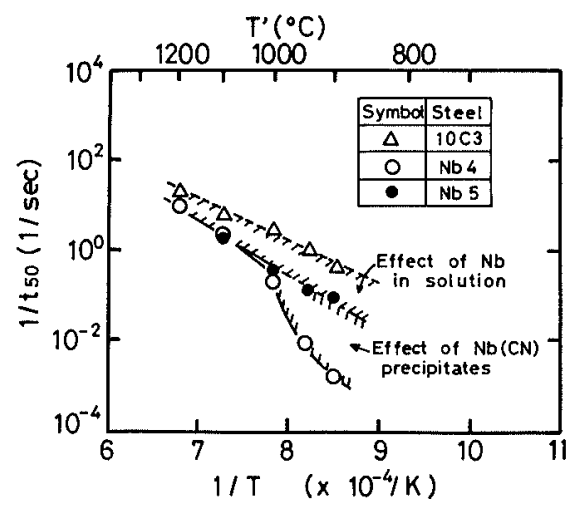

Fig. 15. Arrhenius plot of the reciprocal of half softening time, $1 / t_{50}$, vs. deformation temperature in Kelvin, T.

process is thermal activation process. By using this result, an apparent activation energy, $Q$, is measured according to the following equation (2).

$$
1 / t_{50}=A \exp (-Q / R T)
$$

Here, $R$ : Gass constant

$A$ : a constant.

The activation energy for $\mathrm{Nb}$ and 10C3 steels is 23.8 and $20.7 \mathrm{kcal} / \mathrm{mol}$, respectively. The increase in activation energy due to niobium addition is considered to be caused from $\mathrm{Nb}$ in solid solution. The activation energy for $\mathrm{Nb} 4$ steel is $86.7 \mathrm{kcal} / \mathrm{mol}$ with the deformation temperature below $1000^{\circ} \mathrm{G}$. This value is nearly equal to that of $\mathrm{Nb}$ to diffuse in $\gamma-\mathrm{Fe}$ which is $82.3 \mathrm{kcal} / \mathrm{mol}$. This result indicates that the recrystallization process is governed by the precipitation of $\mathrm{Nb}(\mathrm{CN})$ on dislocations and lattice deffects introduced by hot deformation in such a manner as CCR process. ${ }^{9,14,18)}$ That is to say, the difference in recrystallization process between $\mathrm{Nb} 4$ and $\mathrm{Nb} 5$ below $1000^{\circ} \mathrm{C}$ may originate from the difference in precipitation process of $\mathrm{Nb}(\mathrm{CN})$, and the difference between $\mathrm{Nb} 5$ and 10C3 may originate from the difference in the presence of $\mathrm{Nb}$ in solid solution. In HCR processed $\mathrm{Nb}$ steel with $T_{c}$ above $A r_{1}$, it is shown that the recrystallization temperature is raised upward above $1000^{\circ} \mathrm{G}$ due to the great amount of $\mathrm{Nb}$ in solid solution and large austenite grain size succeeded from solidification. It was shown Fig. 5 that the tough- 
ness was not improved by rolling with the $T_{s}$ below $1000^{\circ} \mathrm{C}$ since the recrystallization did not start at this deformation temperature range and the refinement of austenite grain due to recrystallization did not occur. But when the hot rolling on the first stage was operated sufficiently at the temperature range above $1000^{\circ} \mathrm{C}$ in order to refine the large austenite grain and then done the low temperature range of austenite on the second stage, the toughness would be improved. But, when the hot rolling at too high temperature range above $1000^{\circ} \mathrm{C}$ was done, the toughness was deteriorated in opposition. Because the recrystallized austenite grain size increase with a rise in the deformation temperature. Thus, a rolling start temperature of $1100^{\circ} \mathrm{C}$ is the lower limit of recrystallization, the $v T$ s becomes optimum. But this favorable temperature range of deformation depends upon the amount of deformation reduction, and the temperature range is shifted to lower temperature with increase in deformation reduction as shown in Fig. 9. When such a large austenite grain is deformed below its recrystallization temperature, ferrite grain grows large since the number of ferrite grains nucleated within prior austenite grains is not sufficient enough for the refinement, and it results in the deterioration of toughness.

\section{Summary}

The factor influencing on the strength and the toughness of HCR processed $\mathrm{Nb}$ steel with the charging temperature above $A r_{1}$ is investigated, making clear the metallurgy during HCR process. The main results obtained are as follows.

(1) The change in strength and toughness of HCR processed steels greatly depends upon whether $\gamma-\alpha$ transformation has been completed or not. In case of charging temperature above $A r_{1}$, the toughness is inferior to that of GCR processed one, and $\mathrm{Nb}$ steel shows an increase in strength.

(2) The ratio of Sol. $\mathrm{Nb} /$ Total $\mathrm{Nb}$ ranges from 0.3 to 0.2 in HCR process with the charging temperature above $A r_{1}$. The ratio is similar to that in GGR process at high heating temperature for example $1200^{\circ} \mathrm{C}$, and the increase in the ratio results in the increase in strength.

(3) The deterioration in toughness in HGR processed $\mathrm{Nb}$ steel with the charging temperature above $A r_{1}$ is attributed to the grain coarsening due to the supression of recrystallization which is caused by a large amount of fresh precipitation of $\mathrm{Nb}$.

(4) In order to improve the balance between strength and toughness, the first stage rolling should refine the large austenite grain succeeded from solidifi- cation. It becomes clear that the favorable rolling temperature range is around $1100^{\circ} \mathrm{C}$.

(5) The recrystallization process of large austenite succeeded from solidification during hot rolling depends upon the solidification structure, and the recrystallization is initiated at the region of equiaxial structure at first, and then it propagates outwards to the region of columnar structure as the rolling temperature is raised, or the rolling reduction is increased.

\section{Acknowledgments}

The authours wish to thank Dr. Y. Ito, Senior Managing Director of Sumitomo Metal Industries, Ltd., and Dr. T. Moroishi, Assistant General Manager of R \& D Division for their permission to publish this work. We also wish to thank Dr. H. Ohtani, R \& D Division, for his helpful advice and support, and we also acknowledge Messrs. H. Adachi and F. Goto, R \& D Division, for their technical assistance.

\section{REFERENCES}

1) G. Matsumura, Y. Inoue, S. Sanagi, K. Honda and H. Kato: Tetsu-to-Hagané, 67 (1981), S1194.

2) T. Aritani, H. Hakajima and T. Yamaguchi: Tetsu-toHagané, 68 (1982), \$209.

3) M. Murata, H. Tamehiro and R. Habu: Tetsu-to-Hagané, 72 (1986), A219.

4) Y. Kamada and T. Hashimoto: Tetsu-to-Hagané, 72 (1986), A2,23.

5) K. Kunishige and N. Nagao: Tetsu-to-Hagané, 72 (1986), A227.

6) K. Yamanaka, F. Terasaki, H. Ohtani, M. Oda and M. Yoshihara: Tetsu-to-Hagané, 65 (1979), 1410.

7) H. Suzuki, T. Nishimura and S. Yamaguchi: Tetsu-toHagané, 65 (1979), 2038.

8) Y. Maehara, K. Nakai, K. Yasumoto and K. Mishima: Tetsu-to-Hagané, 73 (1987), 876.

9) Y. Ohmori: J.Jpn. Inst. Met., 30 (1966), 1164.

10) Y. Hashimoto: Tetsu-to-Hagané, 72 (1986), 2081.

11) K. J. Irvine, F. B. Pickering and T. Gladman: J. Iron Steel Inst., 205 (1967), 161.

12) R. A. Djaic and J. J. Jonas: Meiall. Trans., 4 (1974), 621.

13) T. Ohuchi: Tetsu-to-Hagané, 70 (1984), 2081.

14) H. Sekine and T. Maruyama: Telsu-to-Hagané, 58 (1972), 1412.

15) M. Umemoto, H. Ohtsuka and T. Tamura: Tetsu-toHagané, 70 (1984), 557.

16) A. Kelly and R. B. Nicholson: Prog. Mater. Sci., 10 (1961), 149.

17) H. Sekine, T. Maruyama, S. Sekiguchi and T. Ohno: Tetsu-to-Kagané, 56 (1970), 596.

18) J.J. Jonas and I. Weiss: Met. Dci., 13 (1979), 238.

(Originally published in Tetsu-to-Hagané, 74 (1988), 1446, in Japanese.) 